\title{
Convenience and Accuracy: The Dilemma and Exploration of the Work of Identifying Students With Family Economic Difficulties in Colleges and Universities of China
}

\author{
Jingjing Liu ${ }^{1}$ \\ ${ }^{1}$ Department of Students' Affairs, Yancheng Teachers University, Yancheng, China \\ Correspondence: Jingjing Liu, Gongyuandaoyihao, 11\#201, Tinghu, Yancheng, Jiangsu, China.
}

Received: November 30, 2019

Accepted: December 12, 2019

Online Published: December 26, 2019

doi:10.5430/irhe.v4n4p20

URL: https://doi.org/10.5430/irhe.v4n4p20

\begin{abstract}
Students with family financial difficulties, premised on the family economic situation survey, are identified as the basic work of student-funded work in China's higher education stage, which is directly related to who is eligible for financial assistance. In this paper, through questionnaire survey and data analysis, in view of the evaluation of the work methods of students with family financial difficulties in China's higher education stage, and the change in the number of applications of students before and after the policy change, the results of the implementation of the method for identifying students with family financial difficulties in the higher education stage in China were studied before the recent introduction of the government's policy for the benefit of the people. After the implementation of the new policy, the changes and causes of the wishes and behaviors of college students' application for poor students. The study found that: 1 . The way local civil affairs departments reviewed students' family financial situation in the past did not fully guarantee the accurate and reliable results provided by students about family financial situation. 2 . The removal of the local civil affairs department's seal requirement, replaced it as self-reported way, in the short term, did not cause a sharp increase in the number of application of college students to be identified as students with family financial difficulties. 3 . The government needs to establish a unified quantitative calculation method, through the system online application way for students to apply directly, local grass-roots government sampling survey, colleges and universities to assist in the investigation of students' consumption in school, so that make the family financial difficulties students determination work both convenient and accurate.
\end{abstract}

Keywords: financial assistance in higher education, identification of students with family financial difficulties, convenience, accuracy

\section{Introduction}

The work of identification of the poor relate directly to the precision of poverty alleviation projects. Traditionally, poverty has been measured by one dimension: in come. If the income is lower than a certain value, it can be regarded as poor household. In America, the Department of Health and Human Services issues poverty guidelines eachyear. Under updated poverty guidelines for 2019 , the poverty line stands at $\$ 12,490$ for a single personand $\$ 25,750$ for a family of four (Paul Krawzak Tribune News Service, 2019). The UK government, the European Union and many other countries use 60 per cent of median household income as the poverty "threshold" (Joanna Mack). But more and more researchers have found poverty as a multidimensional problem. In UK, one of the most comprehensive measures of poverty on offer at the moment is produced by the Social Metrics Commission (SMC). The SMC is an independent group of experts who have been working to improve the way we understand and measure poverty in the UK, which has been publishing estimates since 2018. They take into account people's incomes, housing and mortgage costs, childcare, costs associated with disability, and accessible savings. They also include rough sleepers in their measure and account for people who live in overcrowded housing (Full Fact). Alkire and Foster proposed several methodologies for multidimensional poverty measurement, the methodology proposed by them which belongs to the axiomatic approach, is the one which has been empirically implemented to the largest scale through the Multidimensional Poverty Index (Sabina Alkire\& Maria Emma Santos, 2013). Researchers in Philippine found using a multilayered perceptron (MLP), as much as 7 out of 10 poor households are positively identified among more than 62,000 households that are randomly included in the test set, seven variables are needed to predict whether a household is poor or not, and three of these variables are related to education(Arnulfo Azcarraga \& Rudy Setiono, 
2018).

In China, the central government has made data explanations for the poor, and has taken the reduction of the poor as an important basis for assessing the governance capacity of governments at all levels. In 2011, the national poverty line standard is 2300RMB per capita annual income (Baidu). The standard of 2855RMB is the lowest poverty alleviation standard in China (ChinaIRN). If the per capita annual income is more than 4000RMB, it means getting rid of poverty (Poverty Alleviation Office of the State Council, 2019). However, these national standards on poverty do not play a role in college student funding. In colleges and universities of China, a large number of students from families exceeding this poverty standard are supported. Chinese colleges and universities are looking for various ways to accurately identify students with family economic difficulties nowadays, as aid in Higher education is an important part of the Chinese student financial assistance. According to the 2018 China Student Funding Development Report, in 2018, pre-school, compulsory education, secondary vocational education, high school, general colleges and universities, in the five sections above, higher education student funding accounted for $44.76 \%$ of the number, $56.3 \%$ of the amount. This is partly because the cost of admission to higher education is higher than in other sections, and the program includes student loans, and on the other hand, it reflects the importance that the state attaches to the financial assistance work of students in higher education. Higher education, as an important way to improve the education level and quality of employment of poor students, has taken on the important function of changing the intergenerational transmission of poverty, and has been placed in more high hopes by the state and all sectors of society. However, with the increase of state, school and social support for college students, some problems in the identification of students with family financial difficulties in colleges and universities have also aroused widespread concern, such as the randomness of the local civil affairs department's seal (Wu Lixun \& Hu Xiangming, 2016). Students who are not poor apply for recognition as poor students in order to obtain financial aid (LU Zhiyong, 2015). Or students were asked to state the specific situation of the family which belonging to personal privacy in front of the class students, and the accuracy and privacy of the difficult students in the identification process have been questioned. Academic circles and subsidizing workers have carried out theoretical thinking and practical exploration in these aspects, but no more scientific, reasonable and universal recognition method has been formed. At present, most colleges and universities in China adopt the method stipulated in the document of the Ministry of education on the identification of students with family economic difficulties in 2007. Based on the questionnaire of family economic situation sealed by the local civil affairs department, the identification work is carried out in the way of individual application, class democratic evaluation, department review and college review, supplemented by family visits, and the evaluation results are publicized within a certain range. Colleges and universities have been in the direction of precision, with home visits, telephone, big data and other ways to understand the difficult situation of students, in order to enhance the accuracy of financial support work (JFDaily, 2019), such as University of Science and Technology of China, Nanjing University of Science \&Technology, XiDian University, Zhengzhou University collected canteen dining information based on the students' campus card. From the data the school administrators found abnormal consumption ones, too high to too low, focus on verification and attention, carry out stealth funding, or cancel the eligibility for assistance, so as to achieve accurate and humanization of funding.

In April 2019, in order to implement the decision-making and deployment of the Party Central Committee and the State Council on reducing certificates for the convenience of the people and optimizing services, according to the requirements of the notice of the general office of the State Council on clearing up certification matters, the Ministry of education clearly cancelled the Ministry of education's clearing up all kinds of certification matters in combination with the actual work in the field of education, and clearly cancelled the notice of the Ministry of finance of the Ministry of education on conscientiously doing a good job in higher education According to the guidance on the identification of students with family economic difficulties (2007), when applying for financial assistance, the Civil Affairs Department of the township, town or street where the family is located shall prove the economic situation of the students' families. The requirement is cancelled, which caused a heated discussion among university financial aid workers. When recognizing the good governance will of the government, there are widespread concerns that this will make it more difficult for colleges and universities to guarantee the accuracy of identify work of students with family economic difficulties. Chinese colleges and universities are in a dilemma: they should not only provide convenience for students in the application process, protect their dignity and privacy, but also ensure that the information provided by students is true. How do students view and evaluate these considerations and initiatives of the government and schools? What should the education and finance departments consider in addition to simply providing financial support?

The main research content of this paper is know the college students' evaluation towards the previous identification method of students with family economic difficulties, their opinion towards the new identification policy, and the 
influence after it was formally implemented.

\section{Research Method}

Before the implementation of the new management method for the identification of students with family economic difficulties, compiled the questionnaire for the establishment of files for students with family financial difficulties in colleges and universities, and in May 2019, the questionnaire was distributed by means of a random online survey, taking the study of students from a local ordinary undergraduate college. Investigate the evaluation of the previous identification method sands and the new method of identification.

After the implementation of the new measures for the identification of students with family financial difficulties, the actual number of applicants is investigated, and the impact of the cancellation of the local civil affairs department's examination on the number of applicants is understood in the light of the changes in the number of students with family financial difficulties in 2015-2019.

\subsection{Self-editing Questionnaire About Identification Work of College Students With Financial Difficulties}

The questionnaire includes the basic information of students, the district where their families are located, whether the file difficult students, the monthly expenditure in school, their view towards the past policy of identification of family financial difficulties students and the evaluation of the file-building work to cancel the local civil affairs department stamp requirements. 846 valid questionnaires were recovered, the proportion of male and female students was: $21.39 \%$ of males, $78.61 \%$ of females, the specific distribution of grades was Table 1 :

Table 1. Distribution of grades

\begin{tabular}{lcc}
\hline \multicolumn{1}{c}{ Grade } & Number & Percentage \\
\hline Freshman & 439 & $51.89 \%$ \\
Sophomore & 225 & $26.6 \%$ \\
Junior & 178 & $21.04 \%$ \\
Senior & 4 & $0.47 \%$ \\
\hline
\end{tabular}

The number of students with family financial difficulties was established, representing 539 persons, $63.71 \%$ of all, and the family locations were distributed as Table 2:

Table 2. Distribution of family locations

\begin{tabular}{lcc}
\hline \multicolumn{1}{c}{ Option } & Number & Percentage \\
\hline Rural & 576 & $68.09 \%$ \\
Town & 112 & $13.24 \%$ \\
County & 68 & $8.04 \%$ \\
City & 72 & $8.51 \%$ \\
Provincial capital city & 18 & $2.13 \%$ \\
\hline
\end{tabular}

Average monthly expenditure of respondents during college, as Table 3. 
Table 3. Monthly cost-of-living expenses during college

\begin{tabular}{lcc}
\hline \multicolumn{1}{c}{ Option } & Number & Percentage \\
\hline Less than 1000yuan & 448 & $52.96 \%$ \\
1000-1500yuan & 317 & $37.47 \%$ \\
$1500-2000$ yuan & 72 & $8.51 \%$ \\
More than 2000yuan & 9 & $1.06 \%$ \\
\hline
\end{tabular}

Evaluation of the financial situation of your family, answers can be found in Table 4 .

Table 4. Self-assessment of family economic situation

\begin{tabular}{lcc}
\hline \multicolumn{1}{c}{ Option } & Number & Percentage \\
\hline wealthy & 4 & $0.47 \%$ \\
Well-off & 232 & $27.42 \%$ \\
Poor & 529 & $62.53 \%$ \\
Very poor & 81 & $9.57 \%$ \\
\hline
\end{tabular}

Table 5. The current application for college students to be identified poor, students themselves need to bring the family economic situation questionnaire to the township civil affairs department to be reviewed and sealed. Combined with what you know about your classmates, do you think this approach guarantees the accuracy of the family basics provided by individuals? (Multi-choice)

\begin{tabular}{lcc}
\hline \multicolumn{1}{c}{ Option } & Number & Percentage \\
\hline $\begin{array}{l}\text { Yes, the identified students who came from financial } \\
\text { difficult families are really poor. }\end{array}$ & 291 & $34.4 \%$ \\
$\begin{array}{l}\text { Basically can, most of the students passed the review } \\
\text { around me are really poor. }\end{array}$ & 454 & $53.66 \%$ \\
$\begin{array}{l}\text { No, some in the file of poor students are not very } \\
\text { poor. }\end{array}$ & 194 & $22.93 \%$ \\
$\begin{array}{l}\text { There are students whose families are financially } \\
\text { difficult, but their families does not have the special } \\
\text { circumstances listed in the document of local civil } \\
\text { affairs department, so cannot pass the review and get } \\
\text { the seal, so cannot set up in file of financial } \\
\text { difficulties in the college. }\end{array}$ & & \\
\hline
\end{tabular}


Table 6. If the file application is to replace the requirement of bring the family situation questionnaire to the local civil affairs department to be sealed, what is your opinion?

\begin{tabular}{lcc}
\hline Option & Number & Percentage \\
\hline Very good, convenient for students. & 255 & $30.14 \%$ \\
No, no guarantee of authenticity. & 214 & $25.3 \%$ \\
With mixed influence & 366 & $43.26 \%$ \\
Don't care about it & 11 & $1.3 \%$ \\
\hline
\end{tabular}

Table 7. For the convenience of students with family financial difficulties, the state stipulates that starting from the fall semester of 2019, students only need to fill out the application form for students with family financial difficulties, and do not need to hold this form to the local civil affairs department to seal the information, which is promised by the student himself and signed. According to this policy, if you do not file, do you have the will to apply for the identification to be poor next time?

\begin{tabular}{|c|c|c|}
\hline Option & Number & Percentage \\
\hline Yes & 653 & $77.19 \%$ \\
\hline No & 117 & $13.83 \%$ \\
\hline No selection & 76 & $8.98 \%$ \\
\hline
\end{tabular}

\subsection{Actual Student Application Data After the New Identification Method Is Formally Implemented}

Compare the student application data after the implementation of the policy with the data for the four years 2015-2018, check their differences, and verify the impact of the implementation of the government's policy for the benefit of students in financial difficult.

In September 2019, the college surveyed, in accordance with the Jiangsu Provincial Education Department and other six departments on the issuance of the Jiangsu Province family financial hardship students identification of the implementation of the work notice (2019), by the students voluntarily fill out the "Application form of family economic hardship students identification and national education funding of Jiangsu Province ", submit the application for identification. The college student is responsible for the authenticity of the information he or she fills in, and does not need to be sealed from the local civil affairs department, that the proof material offered on the basis of his or her own wishes.

In On the basis of individual applications, classes conduct democratic reviews, departments conduct reviews, school management reviews, and eventually 5,610 people set up files for students with difficulties to examine the impact of the new policy and compare the number of students in the five years since 2015. Taking into account that the change in the total number of students in the college will have an impact on the number of students in difficulty, the number of whole students will be as the object of investigation, specific information such as Table 8:

Table 8. Number and proportion of students with family financial difficulties in this college in 5years (2015-2019)

\begin{tabular}{lcc}
\hline Year & $\begin{array}{c}\text { Number of identified poor } \\
\text { students }\end{array}$ & Percentage of students enrolled \\
\hline 2015 & 5966 & $29.29 \%$ \\
2016 & 6269 & $30.70 \%$ \\
2017 & 6312 & $30.50 \%$ \\
2018 & 5866 & $28 \%$ \\
2019 & 5610 & $26.10 \%$ \\
\hline
\end{tabular}




\section{Data Analysis and Discussion}

\subsection{Family Financial Difficulties Are Closely Related to the Place of Origin}

Students with family financial difficulties are mainly come from rural areas. Among the respondents, $63.71 \%$ of students were identified as poor through local civil affairs departments and university audits, close to the percentage of the students' origin in rural areas, $68.09 \%$. Low income of rural presidents in China is a long-term problem to this country, although all levels of government are increasing efforts to alleviate poverty, although the absolute number of farmers' income is growing, there is still a large gap with urban areas, combined with the current urban consumption level and social inflation, the growth of farmers' income cannot achieve long-term income level and quality of life significantly improved. At present, the income growth of farmers is dependent on policy support, the increase of farmers' short-term income does not represent the enhancement of their market competitiveness. The low income level of farmers leads to their lower capacity to bear the expenses of college students than that of urban families. Rural families are more likely to fall into poverty if they have more children or family members who are seriously ill. The rural areas are still the main source of college students with family economic difficulties. Among the respondents, $52.96 \%$ of the students' per capita monthly expenditure was less than $¥ 1000$, which is lower than the average monthly consumption of college students in this province of $¥ 1,208$ (Sohu, 2018) verified their family’s economic income level to a certain extent.

\subsection{The Evaluation of the Accuracy of the Local Civil Affairs Departments Varies Among College Students}

Students' evaluation of the local civil affairs department's method of determining the family's economic situation was generally good, and there were also negative answers. As shown in table 5, the lack of rigor of the audit standards directly lead to the lack of precision of the results. As different local civil affairs departments, or different operators who are responsible for the audit of family financial difficulties have different standards, some may be too strict, some may be too loose. The negative influence of acquaintance relationship also makes it difficult for local civil affairs departments to carry out the identification work in a real objectivity and fairness.

\subsection{College Students Recognize the Government's Willingness to Benefit the People in Need, While Expressing Obvious Concern About Its Impact}

As shown in Table 6, the survey reflects the college students aren't confident in the integrity of their companions, there is a local civil affairs department to review and can't guarantee the accuracy of the identification, completely dependent on the students' subjective application and how can ensure the accuracy of their information?" If one wants to share the aid resources for poor in higher education, it can be achieved simply by filling out the application form, and if there is no abnormal behavior in consuming, the student can easily get what he want will not be disqualified. The availability of student aid resources and the lack of supervision make college students and teachers express concern about the consequences of the government's good will to govern.

\subsection{The Convenience of the Identified Work Has an Encouraging Effect on Some Students' Willingness to Apply}

Of the respondents, $63.71 \%$ were poor students who had set up files for students with family financial difficulties in colleges and universities, and for the new measures for the management of students with family financial difficulties introduced by the state, as shown in table 7 , more than $77 \%$ of the students expressed their willingness to apply for recognition as poor students. There are also some students who are not poor showed their honest side, choose to make corresponding decisions according to their families' true economic situation, do not file applications, and do not enjoy the financial assistance in college.

\subsection{In the First Year of the New Policy, No Significant Increase in the Number of Applicants Was Due to}

In the five-year data for 2015-2019, the number of students identified financially difficult in this college is decreasing. As shown in table 8, from 2015 to 2017, although the number of students identified in poor conditions fluctuated in the college, the percentage was stable, at around 30\%. From 2017 to 2019, both the absolute number of students and the proportion were declining, with the number falling by $7.1 \%$ in 2018 compared to 2017 , and the proportion in 2018 is down $8.2 \%$ from 2017, and in 2019, after the implementation of the new identification scheme aimed at facilitating students in need, the number of students who applied the identification to be financial difficult has decreased by $4.4 \%$, compared to 2018 , and the proportion has fallen by $7.5 \%$, without the significant increase in the number previously feared.

\section{Enlightenment to Practical Work}

\subsection{The Government's Welfare Can Facilitate Students who Are Truly in Trouble}

Since 2007, the implementation of the institutions of higher learning family financial hardship students identification 
management methods, the local civil affairs departments to review and seal as a necessary requirement, the implementation of ten years gradually showed disadvantages, these problems have been felt by college students, in the existing academic research results have been elaborated. Local civil affairs departments audit standards are different, human factors caused by the students can easily seal, some poor students although the family is really difficult, but can't stamp the situation. In the absence of an accurate and verifiable source of information on residents' income, the Government has removed the civil administration's seal requirement through a top-down executive order, with the aim of providing practical convenience to students in real difficulty and ensuring their smooth enjoyment of the government's and university funding policies.

\subsection{Accurate Identification and Identification of Students With Family Financial Difficulties Challenges the Management and Educational Ability of Colleges and Universities}

The qualifications of students with family financial difficulties are the basis work for the implementation of various financial aid projects in colleges and universities. It relate closely with the accuracy of the implementation of many university funding projects, in order to ensure the accuracy of the identification, to confirm whether the students are poor, we can only rely on the university's own ability to identify. High-level universities are ahead of ordinary colleges and universities in their awareness and ability of using data information, and have achieved better response to the use of big data to serve student management and enhance the precision of funding and humanistic care. But the difference between schools makes these practice results difficult to popularize, a large number of poor students or teachers according to the students in the basic consumption performance in school to identify, consumption abnormally high or low easy to cause concern, but the general consumption situation, it is difficult to make accurate judgment, if not accurate identification, not only caused the waste of funding resources, It will also cause bad demonstration effect, which will affect the educational effect of colleges and universities. While encouraging colleges and universities to independently explore the methods of accurate identification of students with family financial difficulties, the competent government departments can learn from the practice of the United States, from the perspective of global, efficient and professional, set up a special household economic investigation department to accept applications for the identification of various groups of students with difficulties at all levels. Use uniform measurement standards and tools to determine the degree of financial hardship of students' families and provide a basis for universities to implement financial lying projects.

\subsection{The Continuity of the Management of Colleges and Universities and Previous Policies Effectively Guarantees the Stability of the Number of Students Applying for the Establishment of Files of Students With Family Financial Difficulties}

Before the new method of identification was formally implemented, teachers and students of college financial support management generally expressed concern about the effect of the implementation of the new policy, but after the late implementation did not occur a sharp increase in the number of people, mainly for the following reasons: First, although the local civil affairs department sealed the requirements, but retained the class democratic review, class teacher, Counselor teacher audit link, these students are more closely linked to the participation of teachers and students, played a role in supervision and warning, not poor students, if there is no sufficient reason, dare not apply arbitrarily. Second, some non-poor students in previous years, has been through various resources, successfully identified as poor students, after the policy changes, they can still through simple individual applications, enjoy the treatment of poor students, so in the number of applications, will not cause a large increase. Third, cognitive habits affect the behavior decision-making of non-poor students. As a group outside the scope of funding policy, non-poor students are influenced by cognitive habits and do not be keenly aware of changes in funding policies, which in turn make changes in behavioral decision-making. The scope of the funding policy has not changed and remains a group of poor students. Non-poor student groups have not previously applied for recognition as students with family financial difficulties, and the impact of changes in funding policies on students' behavior depends on their cognitive habits.

4.4 The Government Establishes an Integrated Income Information System, Constructs Standardized Identification Methods, and Replaces Qualitative Description With Quantitative Data, so as to Effectively Guarantee the Accuracy of the Identification of Students With Family Financial Difficulties

It is determined that the main body has been changed from a university to a government department, because the work of students with family financial difficulties is related to the implementation of various funding policies, especially the implementation of state-level funding projects, and the university as a teaching unit, students from all over the country, cannot verify the actual income of the student family one by one, The government department, as the main body to determine whether students and their families are poor, is more in line with the government's 
function of poverty relief, and is more feasible in economy and effectiveness, and can also free colleges and universities from the identification work and focus on educating students.

Replace qualitative descriptions with quantitative data. The actual income level of the student's family is the decisive factor to determine whether the student is able to bear the basic expenses during the school period, the government-led, the establishment of an integrated income information system, the construction of standardized identification methods, the establishment of a national identification system, single parents, low-income, pure farmers, The common qualitative description, such as many children, translates into the actual income and expenditure data of the family, according to the average expenditure of the students in ordinary colleges and universities, calculates the ability of the students and their families to bear the expenses of the students to go to school, and determines the suitable financial support projects, which is the inevitable way for the object of college students' financial aid and the precision of the project.

Replace disclosure of personal statements with a systematic audit. Students apply directly in the national unified system, instead of in front of classmates as the teachers asked, can avoid the excessive exposure of personal privacy which tends to bring moral harm to the applicants, as well as peer groups of "moral kidnapping", make poor students dare not have some expenditure higher than others, such as apply for going abroad exchanges programs and other development-oriented expenditure. Class review and publicity is not only one way of supervision, but also easily to produce public opinion pressure, to bring spiritual burden to the applicants.

\section{Acknowledgements}

This work is supported by Jiangsu Education Science 13th Five-Year plan 2018 (Key funding project of Student financial aid special topics). The project name: Study on the identification of students with family financial difficulties in colleges and universities under the idea of precision financial support. The project number: $\mathrm{X}-\mathrm{a} / 2018 / 19$. This study is a phased result of the project.

\section{References}

2018 China Student Funding Development Report. (2019). Ministry of education of China. Retrieved from http://www.xszz.cee.edu.cn/index.php/shows/70/3716.html

Alkire, S., \& Santos, M. E. (2013). A Multidimensional Approach: Poverty Measurement \& Beyond. Social Indicators Research, 112, 239. https://doi.org/10.1007/s11205-013-0257-3

Arnulfo Azcarraga, \& Rudy Setiono. (2018). Neural network rule extraction for gaining insight into the characteristics of poverty, Neural Computing and Applications. 30, 2795-2806. https://link.springer.com/article/10.1007/s00521-017-2889-8

Baidu. Poverty standard in China. Retrieved from https://baike.baidu.com/item/poverty standard in China/1207599?fr=aladdin

Colleges and universities look for students with family financial difficulties through big data whose meal card is 720 yuan more? (2019) Jfdaily. Retrieved from wje.sciedupress.com

Guiding opinions of the Ministry of education and other six departments on the identification of students with family economic difficulties. (2018). Ministry of Education of the People's Republic of China. 07-11-2018. Retrieved from https://www.chsi.com.cn/jyzx/201811/20181107/1736219869.html

Guiding opinions on the identification of students with family economic difficulties in Colleges and Universities. (2007). Ministry of Education of the People's Republic of China\& Ministry of Finance of the People's Republic of China. Retrieved from http://old.moe.gov.cn/publicfiles/business/htmlfiles/moe/moe_1581/200708/25283.html

In 2019, the Ministry of education cancelled a batch of certification matters, you must know. 25-4-2019. Retrieved from http://www.sohu.com/a/310294521_490039

Joanna Mack. Income threshold approach. Retrieved from http://www.poverty.ac.uk/definitions-poverty/income-threshold-approach

Lu, Z. (2015, Dec.). Problems and possible resolving strategies in the identification of students accessible to aiding projects in colleges and universities. Journal of Hunan Agricultural University (Social Sciences), 16(6), 90-93. https://doi.org/10.13331/j.cnki.jhau(ss).2015.06.015

Paul Krawzak Tribune News Service. Trump wants to update poverty thresholds. It could affect food stamps and Medicaid benefits. Retrieved

from 
https:/www.saukvalley.com/2019/05/13/trump-wants-to-update-poverty-thresholds-it-could-affect-food-stamps -and-medicaid-benefits/akb0t7h/

Poverty Alleviation Office of the State Council: in 2020, the income from poverty alleviation of poor households will reach 4000 yuan (per capita annual income in rural areas). (2019).China.com.cn. 07-03-2019. Retrieved from http://finance.sina.com.cn/roll/2019-03-07/doc-ihrfqzkc1921223.shtml

Poverty in the UK: a guide to the facts and figures. Full Fact. 27th Sep 2019. Retrieved from https://fullfact.org/economy/poverty-uk-guide-facts-and-figures/

The average monthly cost of living of college students in all provinces of the country. (2018). Retrieved from http://www.sohu.com/a/250279328?10019890

Two sessions in 2019: This year, we will reduce the poverty alleviation target by another 10 million people. What is the poverty alleviation standard for the poor? 2019. ChinaIRN. 08-03-2019. Retrieved from http://www.chinairn.com/news/20190308/152731233.shtml

Wu, L., \& Hu, X. (2016). Research on Implementation Effect of Aid Policies for Needy Students in Universities --Based on the Investigation of Some Graduates in Beijing. Journal of National Academy of Education Administration, (2), 72-78. https://doi.org/10.3969/j.issn.1672-4038.2016.02.014. 